\title{
A COMPRAVENDA DE TERRAS RÚSTICAS NAS ZONAS DE ESPECIAL INTERESE AGRARIO DE GALICIA: OS TRAZOS DUN NOVO MAPA SOBRE UN VELLO PRECEPTO*
}

María José ENRÍQUEZ GARCÍA,

Laboratorio do Territorio. Departamento de Enxeñería Agroforestal. Universidade de Santiago de Compostela - Campus de Lugo,.mariajose.enriquez.garcia@usc.es Eduardo José CORBELLE RICO,

Laboratorio do Territorio. Departamento de Enxeñería Agroforestal. Universidade de Santiago de Compostela - Campus de Lugo, eduardo.corbelle@usc.es.

\section{Resumo.}

Os mercados son un instrumento clásico de distribución dos dereitos de propiedade. Non obstante, nas zonas de alta fragmentación da propiedade tamén se avalía a súa eficiencia como instrumento de reorganización parcelaria. En Galicia, esta diagnose non se abordou nas últimas tres décadas e persiste o precepto de baixa mobilidade. Este traballo debuxa o mapa de taxas de transferencia e prezos de compravenda a nivel concello e parroquia para as zonas declaradas pola Lei 7/ 2007 como zonas de especial interese agrario de Galicia no período 2008-2011. O precepto de baixa mobilidade matízase pola diversidade de valores territoriais e por unha marcada relación inversa entre a taxa de transferencia e o prezo. Se ben a mobilidade de terras é baixa cando se mide en termos de superficie, non é tal respecto do número de parcelas. En determinadas áreas, o mercado non só se articula entorno a superficies agrarias senón que tamén se mobiliza superficie sen uso agrario actual. O tamaño da parcela, a copropiedade e, especialmente o absentismo, son características do parcelario que condicionan o volume e prezo das transaccións. Por último, a diagnose espazo-temporal do mercado esixe considerar a compravenda en relación a outros mecanismos de mobilidade (arrendamento, parcería, cesións...)

Palabras clave: mercado de terras, taxa de transferencia, mobilidade, fragmentación da propiedade

Title: Rural land market in areas of special agricultural interest in Galicia: outlining a new map over an old prescript

\section{Abstract.}

Land markets are a classic mechanism of property rights distribution. Nevertheless, their efficiency is also evaluated as a mechanism of parcel reorganization in regions with land fragmentation problems. Particularly, this diagnosis has not been done in Galicia and the prescript of low land mobility persists since the nineteens. This paper draws a map of land sale rates and prices at municipal and parish scale in areas which where declared by regional law as areas of special agricultural interest during the period 2008-2011.Low land mobility prescript is tempered by the territorial diversity of values and a strong inverse relationship between transfer rates and prices. In general, land sale rate is low when it is measured in terms of area, but this not happen when considering the number of plots. In certain areas, land market not only implies mobilizing agricultural land but also parcels without current agricultural use. The size of the plot, co-ownership and, especially, absentee regimes seem to be characteristics of properties that determine both volume and price of transactions. Finally, spatiotemporal diagnosis of land markets requires consider land sales in relation to other land mobility mecanism (lease, sharecropping, communal lands...)

Key words: land market, land transfer rate, land mobility, land fragmentación 


\section{Introdución}

A posta en marcha de complexos sistemas de rexistro e administración de terras considérase unha premisa para a creación de economías estables (Bogaerts, Williamson e Fendel, 2002; Deininger, 2003) e, en particular, para a articulación de mercados de terras dinámicos e eficientes (Peter Dale e Baldwin, 2000; Wallace e Williamson, 2006). O interese pola evolución das dinámicas do mercado de terras no contexto da Política Agraria Común fixo que se incorporasen indicadores específicos a estatísticas como EUROSTAT. Ademais tense analizado mediante múltiples estudos comparativos a nivel nacional, especialmente no caso dos países en transición (Ciaian e Swinnen, 2006; Ciaian, Kancs e Swinnen, 2010; Bojnec, 2011; Ciaian et al., 2012).

Precisamente, a concepción do mercado de terras como instrumento de reorganización parcelaria, e non só como mecanismo de redistribución dos dereitos de propiedade, xustifica o prolífico número de estudos científico-técnicos en contextos de alta fragmentación da propiedade (Csaki e Lerman, 2000; Kopeva, 2003; Dirimanova, 2004). $O$ número e tamaño das parcelas, o abandono do uso agrario, a copropiedade ou o absentismo características do parcelario con impacto nas no funcionamento mercado de terras destas rexións (Vranken, Noev e Swinnen, 2004; European Environment Agency, 2010; Vranken et al., 2011).

Á par que se institucionalizaban metodoloxías de seguimento e diagnose, o volume e diversidade de instrumentos de xestión deseñados para abordar estes obstáculos ían en aumento (concentración parcelaria, bancos de terras, zonificación e regulación de usos, reducións fiscais, incentivos ao cooperativismo e asociacionismo...)(Van Dijk e Kopeva, 2006; Swinnen, Herck e Vranken, 2012). Deste xeito, o paradigma de gobernanza de terras actual integra a administración e xestión nun modelo conxunto multipropósito (Williamson et al., 2010).

Galicia representa o $6 \%$ da superficie rústica de España e o 20 e $28 \%$ de titulares catastrais e parcelas, respectivamente (DGC, 2015); ten un promedio de 7 parcelas de 0,25 ha de superficie media por titular e perdeu 145.840 ha de Superficie Agraria Útil entre 1985 e 2005 (Corbelle e Crecente, 2014). Por ende, é un caso representativo de ambas realidades: fragmentación do parcelario e da propiedade e perda de superficie de uso agrario.

De igual xeito que nas rexións centroeuropeas con similares características, as dúas principais liñas de investigación en materia de ordenación e planificación do sector agrario en Galicia foron a reestruturación técnico-económica das explotacións agroforestais dende os anos sesenta (Sineiro, 1983; López, 1996; Lorenzana et al., 2004; Vázquez et al., 2012) e, recentemente, as dinámicas de uso do solo (abandono do uso agrario, forestación con especies de crecemento rápido, procesos de urbanización ou cambios na paisaxe) (Marey, Vicente e Crecente, 2007; Calvo, 2010; Corbelle e Santé, 2010; Corbelle e Crecente, 2014). Consecuentemente, deseñáronse e puxéronse en marcha instrumentos de xestión de terras, como a concentración parcelaria (Miranda, Crecente e Álvarez, 2006) ou o banco de terras (Ónega, Oliveira e Crecente, 2010).

Ambas liñas, investigación e xestión, construíronse sobre o precepto de baixa mobilidade de terras establecido por López Iglesias (1995) para o peíodo 1987-1988. Dende entón, o funcionamento do mercado de dereitos de propiedade non volveu ser obxecto de análise a pesar de : 1) a proliferación de políticas e de rexistros masivos de información asociados (catastro, SIGPAC, impostos de transmisións, índices notariais, ...); 2) de que os traballos previos apuntaban á diversidade territorial de dinámicas (Pérez, 1987; Torres e Lois, 
1992; López, 1996) e 3) de que as características do parcelario en Galicia (tamaño da parcela, uso, copropiedade, absentismo) foron abordadas pola bibliografía de xeito recorrente (Planchuelo, 1971; Villares, 1982; O'Flanagan, 1996; Crecente, 2010).

A creación do Banco de Terras de Galicia no ano 2007 e, en particular, o dereito de adquisición preferente (dereito de tenteo e retracto) en todas as transmisións inter vivos de predios rústicos en zonas consideradas Zonas de Especial Interese Agrario (ZEIA) configurou unha base de datos de transaccións de compravenda idónea para a caracterización do mercado de terras rústicas no período 2008-2011. As zonas ZEIA delimitáronse como as zonas de alta produtividade agrícola ou gandeira posta de manifesto pola existencia de explotacións como aval da potencialidade, as zonas obxecto de concentración parcelaria ou calquera outra zona declarada mediante decreto do Consello da Xunta.

O obxectivo do traballo é estudar o mercado de terras mediante compravenda nas zonas de especial interese agrario de Galicia. En particular, estimar a taxa de transferencia e prezo e comparalos co de outras rexións de España e Europa; avaliar a súa variabilidade territorial e determinar como se comportan ambos indicadores segundo determinadas características da estrutura da propiedade e réxime de tenza (superficie da parcela, uso, copropiedade e absentismo).

\section{Material e método}

\subsection{Material}

Durante o período de vixencia do dereito de tenteo e retracto de fincas rústicas por parte do Banco de Terras de Galicia (2007-2011) foron declaradas mediante decreto trinta e sete comarcas, que suman case tres cuartas partes do territorio galego e o $80 \%$ da Superficie Agraria Útil.

A declaración fíxose mediante tres decretos ${ }^{1}$, en outubro e decembro de 2007 (cinco e dezaseis comarcas, respectivamente) e outro en decembro de 2008 (dezaseis comarcas). Para o tratamento dos datos, as comunicacións recibidas no período 2008 a 2011 consideráronse anualidades completas e tívose en conta que os valores do ano 2008 están referidos a dezaseis comarcas menos que os das anualidades 2009, 2010 e 2011.

Os datos rexistrados para cada transacción constan de: información da parcela (referencia catastral, concello, parroquia, superficie obxecto de compravenda e uso declarado polo vendedor no momento da transacción); información sobre os axentes (número de compradores e vendedores e concello de residencia de cada un deles) e información sobre a transacción (data e prezo declarado).

A fonte de datos presenta as seguintes limitacións: 1) só se rexistra a mobilidade de terras mediante compravenda, e incluso dentro desta, só compravendas formalizadas en documento escrito ante notario e comunicadas a instancia de parte no período 2008-2011

1 Decreto 206/ 2007, de 25 de octubre, por el que se declaran como zonas de especial interés agrario las comarcas de Ordes, A Terra Chá, A Limia, O Deza y O Baixo Miño

DECRETO 263/ 2007, de 28 de diciembre, por el que se declaran como zonas de especial interés agrario las comarcas de Arzúa, A Barcala, Melide, Xallas, Chantada, A Fonsagrada, Meira, Terra de Lemos, 0 Ribeiro, Terra de Caldelas, Terra de Celanova, Verín, Caldas, O Condado, O Salnés e Tabeirós-Terra de Montes

DECRETO 293/ 2008, de 18 de diciembre, por el que se declaran como zonas de especial interés agrario las comarcas de Bergantiños, Barbanza, Eume, Muros, Noia, Santiago de Compostela, O Sar, Os Ancares, Lugo, Sarria, A Ulloa, Allariz-Maceda, Baixa Limia, Terra de Trives, A Paradanta y Pontevedra 
(non constan as realizadas mediante documento privado ou contrato oral) e 2) as transaccións obxecto de notificación quedan circunscritas ás zonas declaradas ZEIA e non á totalidade do territorio galego.

\subsection{Método}

O mercado de terras neste traballo analízase a través da taxa de transferencia anual (\%) e prezo por unidade de superficie $\left(€ / \mathrm{m}^{2}\right)$. Ambos indicadores estimáronse para os ámbitos territoriais permitidos pola base de datos: total para zonas ZEIA, concello e parroquia.

A taxa de transferencia definiuse respecto da superficie e do número de parcelas como a proporción de superficie obxecto de compravenda en relación ó total do ámbito territorial considerado (Ciaian, Kancs e Swinnen, 2010; Swinnen, Herck e Vranken 2012) e como a proporción do número de operacións de compravenda respecto do número de parcelas catastrais (Wunderlich, 1990; Dale e Baldwin, 2000).

A superficie agroforestal de cada concello obtívose do desglose segundo usos dos Anuarios de Estatística Agraria (Xunta de Galicia, 2011) e o número de parcelas de rústica de cada concello das Estatísticas da Dirección Xeral de Catastro (DGC, 2015). A estimación da taxa de transferencia de superficie a nivel de parroquia fíxose a través dos datos de superficie parroquial do Instituto Galego de Estatística e estivo limitada pola inexistencia de estatísticas de uso do solo e catastrais a dita escala.

Para o cálculo da taxa de transferencia de superficie segundo usos, as oitenta e catro categorías de uso que figuraban no correspondente campo da base de datos agrupáronse en tres clases xenéricas: agrario (terras de cultivo, prados, viñedo...), mato (vexetación leñosa ou uso mixto, tales como pasto arbustivo baixo arborado) e forestal. As parcelas declaradas con uso urbano ou improdutivo no momento da compravenda foron descartadas da análise. Deste xeito, calculouse a taxa xeral de uso agroforestal e, ademais, debullouse para uso agrario, mato e forestal a nivel concello.

A compoñente territorial dos indicadores avaliouse mediante a súa representación nun mapa de concellos e parroquias; a estimación do coeficiente de variación municipal das taxas de transferencia parroquiais e, finalmente, a análise de conglomerados dos concellos en función dos tres indicadores (taxa, prezo e coeficiente de variación da taxa de transferencia parroquial).

O coeficiente de variación municipal é a relación entre a desviación estándar e a media da taxa de transferencia das parroquias de cada concello, en tanto por dez mil para evitar valores do denominador moi baixos.

A obtención de tres grupos de concellos homoxéneos abordouse mediante unha análise de conglomerados empregando a distancia euclídea entre observacións e o método de mínima varianza de Ward. Previamente, os indicadores foron estandarizados polo procedemento de restar a súa mediana e dividir pola desviación absoluta mediana.

Finalmente, analizouse o comportamento dos indicadores en función do tamaño, uso e réxime de copropiedade e absentismo da parcela. A condición de copropiedade foi definida antes e despois da transacción como aquelas operacións nas que existe máis dun vendedor e comprador, respectivamente. As parcelas en réxime de absentismo definíronse como aquelas nas que máis do $50 \%$ dos propietarios residen nun concello diferente ó de localización da parcela, posto que na base de datos non se dispón de información sobre o coeficiente de participación de cada propietario. 


\section{Resultados}

\subsection{Taxa de transferencia}

As 23.513 parcelas obxecto de compravenda no período 2008-2011 sumaron un total de 7.867 ha (0,39 \% da superficie das zonas ZEIA e o 0,27 \% do territorio galego).

A taxa de transferencia de superficie agroforestal media anual das zonas ZEIA é do 0,10 \%. Este valor enmascara unha ampla diversidade territorial de valores na que se acada un máximo do 1,18 \% municipal e un 7,33 \% parroquial (Mapa 1). Polo contrario, a taxa de transferencia estimada respecto do número de parcelas presenta valores territoriais moito máis homoxéneos que non superan o 0,58 \% en ningún dos concellos das zonas ZEIA.
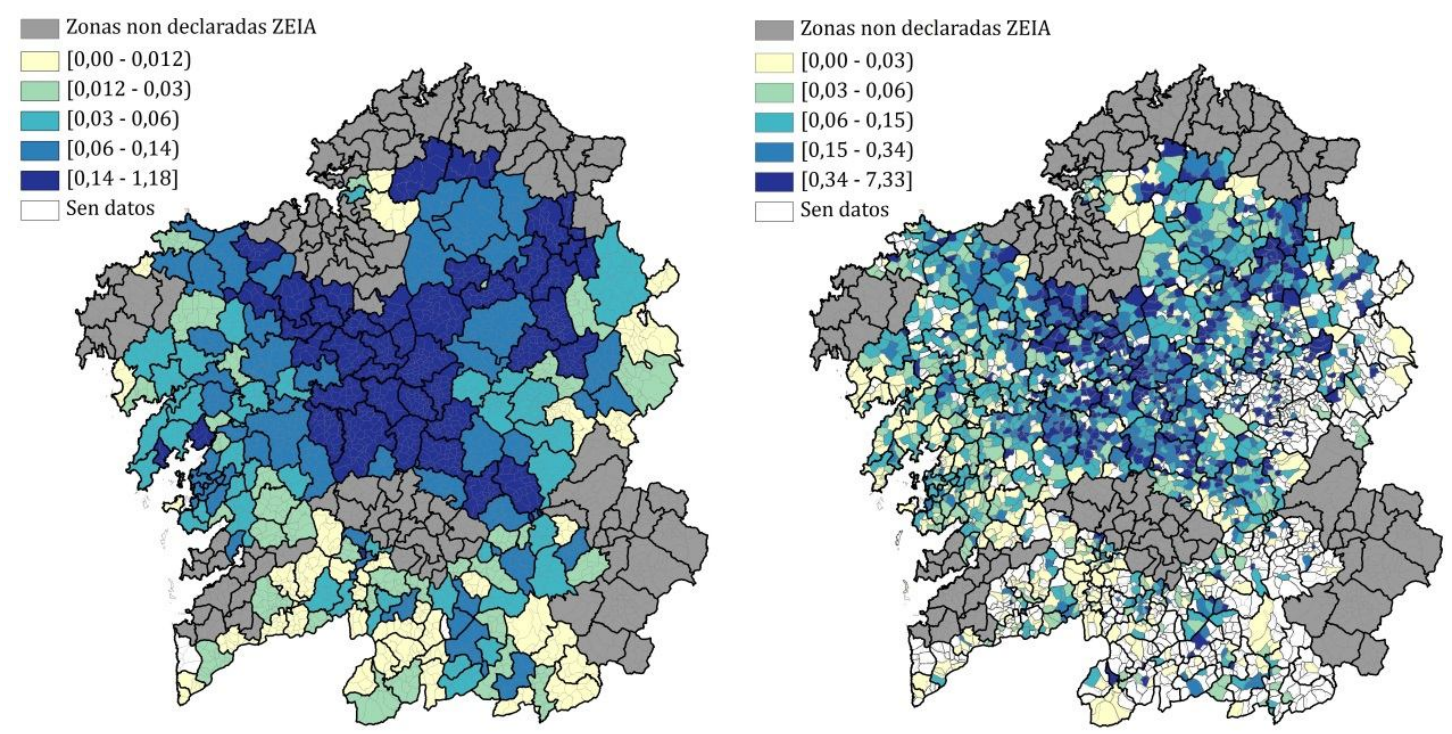

Mapa 1. Taxa de transferencia de superficie agroforestal media anual (\%) por concello (esquerda) e parroquia (dereita). Fonte: elaboración propia a partir dos datos de adquisición preferente do Banco de Terras de Galicia do período 2008-2011.

O rango de valores anuais da taxa de transferencia agraria e de mato no período 20082011 é de $0,14-0,20 \%$ e 0,12-0,23 \%, respectivamente. A taxa de transferencia para uso forestal móvese entre o 0,02 e o $0,06 \%$.

O tamaño medio das parcelas obxecto de compravenda é de 0,35 ha $(0,28$ ha as de uso agrario; 0,48 ha as de mato e 0,40 as forestais). O tamaño mediano é de 0,12 ha ( 0,11 ha as de uso agrario; 0,15 ha as de mato e 0,13 as de uso forestal). $093 \%$ das parcelas teñen unha superficie inferior a 1 ha e suman o $50 \%$ da superficie obxecto de compravenda do período.

O $11 \%$ da superficie obxecto de compravenda tiña máis dun propietario antes da transacción e, despois desta, un $6 \%$ mantén o réxime de copropiedade. Os fluxos de cambio entre un réxime e outro foron tal que un $9,3 \%$ da superficie pasou a propietario único mentres que un 3,5\% mudou a réxime de copropiedade. Non se observan diferenzas apreciables na proporción de superficie en réxime de copropiedade segundo tamaños de parcela ou uso. 
O $40 \%$ da superficie obxecto de compravenda no período 2008-2011 era de propietarios que residían nun concello diferente ó de localización da parcela e a proporción mantense nun $30 \%$ logo da transacción. O fluxo de cambio foi tal que un $22 \%$ da superficie pasou de propiedade absentista a residente e un $12 \%$ á inversa. A taxa de absentismo en relación ó uso e tamaño revela que o $50 \%$ da superficie agraria se transmitiu entre residentes; a proporción de superficie de uso agrario en réxime de absentismo despois da compravenda mantense nun $27 \%$ e, paradoxicamente, a proporción de superficie en réxime absentista aumenta conforme aumenta o tamaño da parcela (dende o $37 \%$ das de menos de 0.5 ha ata o $55 \%$ das de 5-10 ha).

\subsection{Prezo}

O prezo medio do período 2008-2011 é de 6,95 €/ $\mathrm{m}^{2}$. Posto que a variabilidade dos datos é alta e a distribución está sesgada positivamente óptase polo valor mediano como mellor estimador do prezo: $1,13 € / \mathrm{m}^{2}$ (Gráfico 2).

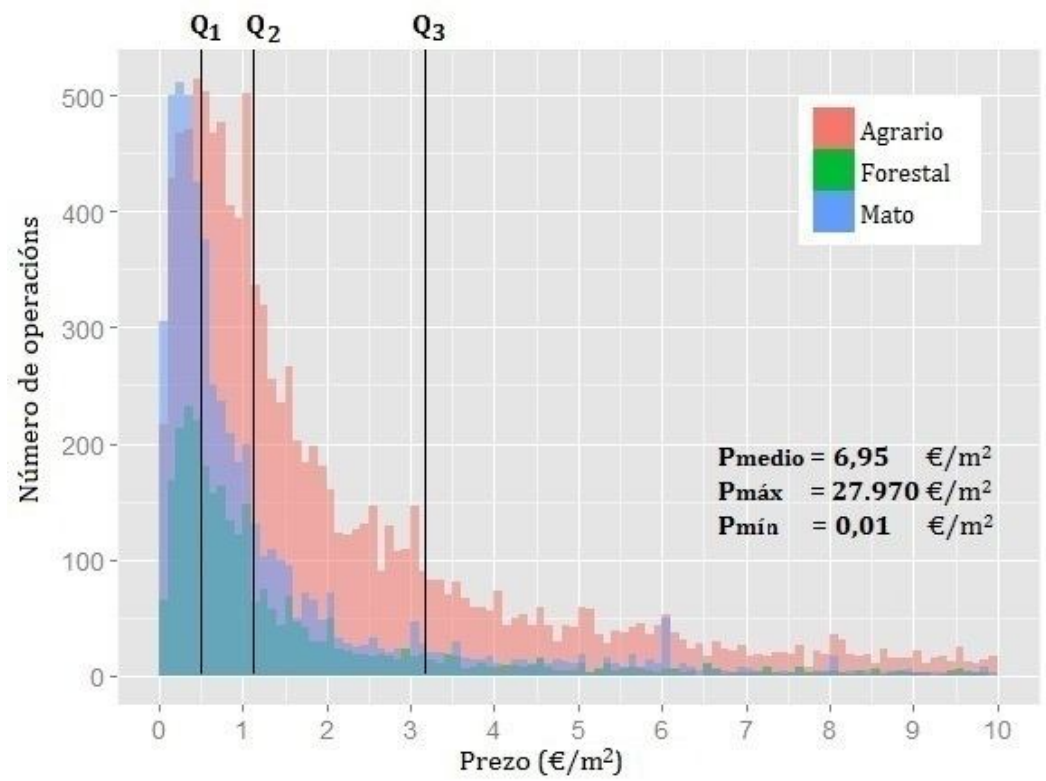

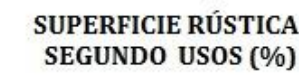
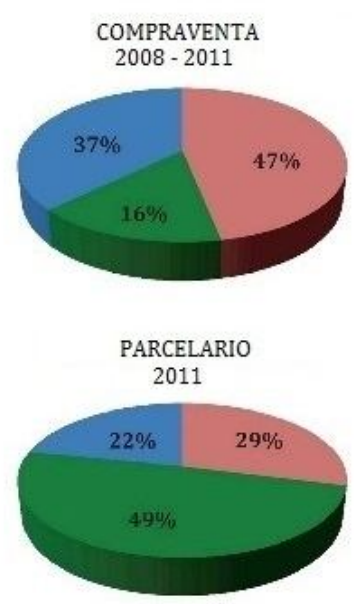

Gráfico 2. Histograma de prezos de compravenda no período 2008-2011 segundo uso declarado das parcelas, incluíndo o valor dos cuartiles do conxunto total de valores $\left(\mathrm{Q}_{1}, \mathrm{Q}_{2}\right.$ e $\mathrm{Q}_{3}$ ) (esquerda). Elaboración propia a partir dos datos de adquisición preferente do Banco de Terras de Galicia. (b) Distribución da superficie rústica segundo usos no universo de compravenda dos datos de adquisición preferente do Banco de Terras de Galicia e do parcelario total para as zonas ZEIA (IGE, 2011) (dereita).

O prezo mediano de terras de uso agrario $\left(1,54 € / \mathrm{m}^{2}\right)$ duplica ó de uso forestal $(0,85$ $\left.€ / \mathrm{m}^{2}\right)$ e de mato $\left(0,69 € / \mathrm{m}^{2}\right)$. As parcelas con rango de valores máis amplo e diverso son as de menos de $0,5 \mathrm{ha}$, cun prezo mediano de $1,29 € / \mathrm{m}^{2}$. A partir dese tamaño o prezo mediano estabilízase entorno ós $0,63 € / \mathrm{m}^{2}$, ata os $0,32 € / \mathrm{m}^{2}$ das escasas parcelas de máis de 10 ha.

As parcelas compradas en réxime de copropiedade teñen un prezo mediano $\left(1,34 € / \mathrm{m}^{2}\right)$ superior a cando son mercadas por un propietario único $\left(1,12 € / \mathrm{m}^{2}\right)$. Esta pauta é xeral, mantense para todos os usos e tamaños de parcela. 
O prezo mediano é lixeiramente superior cando o vendedor é residente $\left(1,21 € / \mathrm{m}^{2}\right)$ a cando é absentista $\left(1,00 € / \mathrm{m}^{2}\right)$. En particular, para uso agrario, cando a propiedade pasa de residentes a absentistas (3,4 \% da superficie e $12 \%$ das parcelas de uso agrario) o prezo mediano ascende ata os $2,09 € / \mathrm{m}^{2}$. Nos casos restantes, o prezo mediano agrario rolda os $1,50 € / \mathrm{m}^{2}$, incluso cando se produce entre residentes.
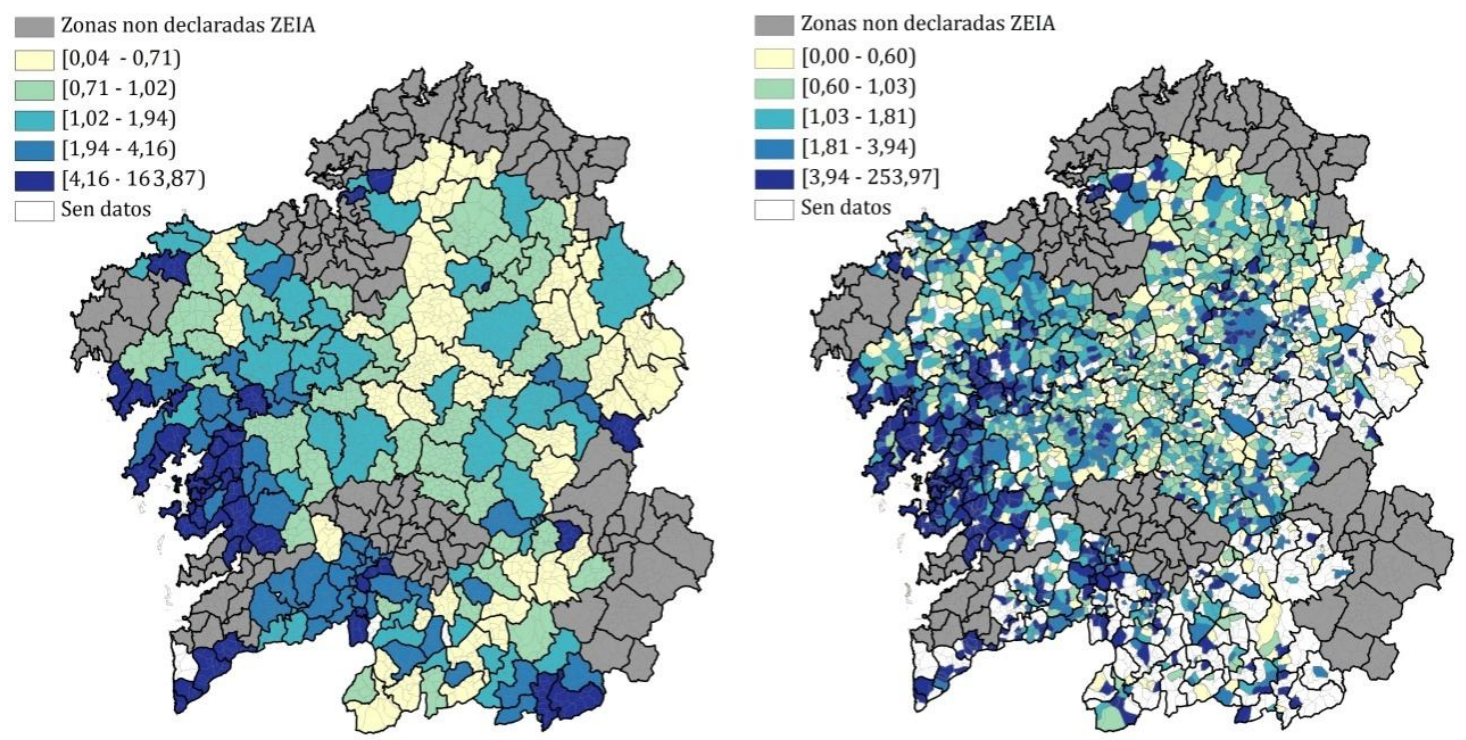

Mapa 3. Prezo mediano ( $\left.€ / \mathrm{m}^{2}\right)$ por concello (esquerda) e parroquia (dereita) das zonas ZEIA no período 2008-2011. Elaboración propia a partir dos datos de dereito de adquisición preferente do Banco de Terras de Galicia.

\subsection{Análise territorial}

Tanto a taxa de transferencia de superficie agroforestal como o prezo presentan unha marcada diferenciación territorial dos valores, tanto a nivel de concello como de parroquia. Ademais, ambos mapas debuxan un mapa aproximadamente inverso (Mapa $1 \mathrm{e}$ 3).

A mobilidade neta mediante compravenda dos concellos concéntrase en determinadas parroquias, especialmente nas provincias de Lugo e Ourense.

A análise de conglomerados aplicada sobre os indicadores a nivel concello (taxa de transferencia agroforestal (\%), prezo $\left(€ / \mathrm{m}^{2}\right)$ e coeficiente de variación das taxas de transferencia parroquiais) definiu tres grandes rexións ou bloques territoriais que denominamos: occidental (ou eixo atlántico), central e suroriental (Mapa 4).

O bloque de concellos occidentais, ou eixo atlántico, caracterízase por uns valores de taxa de transferencia de superficie agroforestal baixa e homoxénea en todas as súas parroquias. Este bloque presenta o rango de valores de prezo de maior amplitude e unha mediana lixeiramente superior ó resto. O bloque de concellos central representa o caso inverso, agrupa os concellos de maiores taxas de transferencia e os prezos máis baixos e similares. Neste caso, o valor medio da taxa de transferencia é alto e homoxéneo en todas as parroquias. A diferenza dos anteriores, o bloque suroriental representa un conxunto de concellos nos que a compravenda de terras se concentra en determinadas parroquias, por iso é polo que a taxa de transferencia neta a nivel concellos é baixa, ó igual que os prezos. 
Grupo de concellos

Zonas non declaradas ZEIA

1 - Bloque occidental

2 - Bloque central

3 - Bloque suroriental

Sen datos
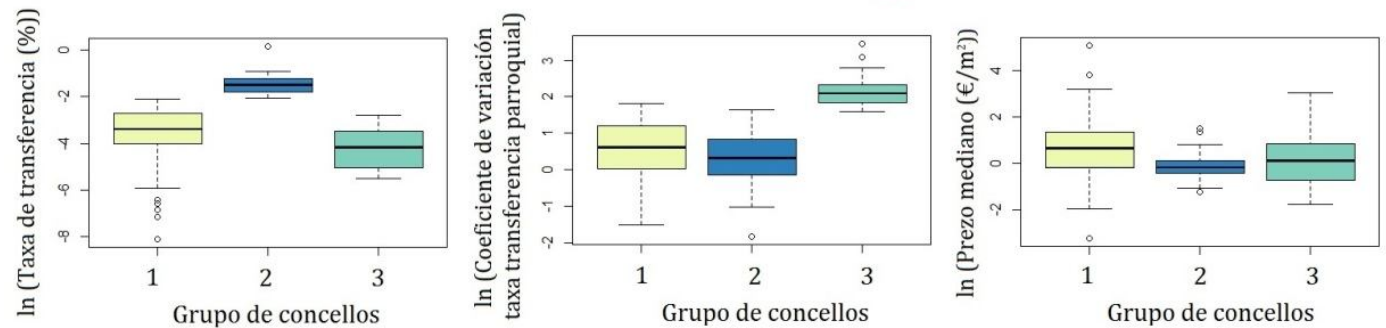

Mapa 4. Grupos de concellos resultantes da análise de conglomerados a partir dos indicadores do mercado de terras mediante compravenda (taxa de transferencia, prezo e coeficiente de variación municipal da taxa de transferencia parroquial). Elaboración propia a partir dos datos de adquisición preferente do Banco de Terras de Galicia no período 2008-2011.

\section{Discusión}

\subsection{Taxa de transferencia}

Non semella que as zonas de especial interese agrario concentren o dinamismo do mercado de terras rústicas pois representan case o $75 \%$ do territorio galego e, como media anual, tamén o $70 \%$ das operacións de compravenda de terras rústicas de Galicia segundo os datos da Estatística Estatística de Transmisións de Dereitos de Propiedade (INE, 2015) (Táboa 5). 
Táboa 5. Número de operacións de compravenda e taxa de transferencia de parcelas nas zonas ZEIA e o total en Galicia. Elaboración propia a partir dos datos de dereito de adquisición preferente do Banco de Terras de Galicia e da Estatística de Transmisións de Dereitos de Propiedade (INE, 2015), respectivamente.

\begin{tabular}{|c|c|c|c|c|c|}
\hline Ano & $\begin{array}{c}\text { № de ops. } \\
\text { ZEIA }\end{array}$ & $\begin{array}{c}\text { № ops. } \\
\text { Galicia }\end{array}$ & $\begin{array}{c}\text { ZEIA/ Galicia } \\
(\%)\end{array}$ & $\begin{array}{c}\text { Taxa transf. } \\
\text { ZEIA (\%) }\end{array}$ & $\begin{array}{c}\text { Taxa transf. } \\
\text { Galicia (\%) }\end{array}$ \\
\hline 2008 & $4.111^{*}$ & 11.224 & $37 *$ & 0,082 & 0,223 \\
\hline 2009 & 6.085 & 8.376 & 73 & 0,075 & 0,103 \\
\hline 2010 & 7.753 & 8.134 & 95 & 0,097 & 0,102 \\
\hline 2011 & 5.539 & 8.066 & 69 & 0,070 & 0,101 \\
\hline
\end{tabular}

* No ano 2008 foran declaradas zonas ZEIA 21 comarcas. Nas anualidades 2009-2011, o número de comarcas ZEIA declaradas elevouse a 37, de aí a diferenza no número de operacións.

O dinamismo do mercado de terras mediante compravenda, analizado como a taxa de transferencia do número de parcelas, é homoxéneo en todo o territorio galego e toma valores, inda que baixos, similares ó de outras rexións do norte peninsular (Mapa 6). En xeral, a amplitude do rango de valore dista moito do 4,6 \% estimado por Wunderlich (1990) para Estados Unidos no ano 1987 ou do 7 \% que Dale e Baldwin (2000) establecen como óptimo para Europa.
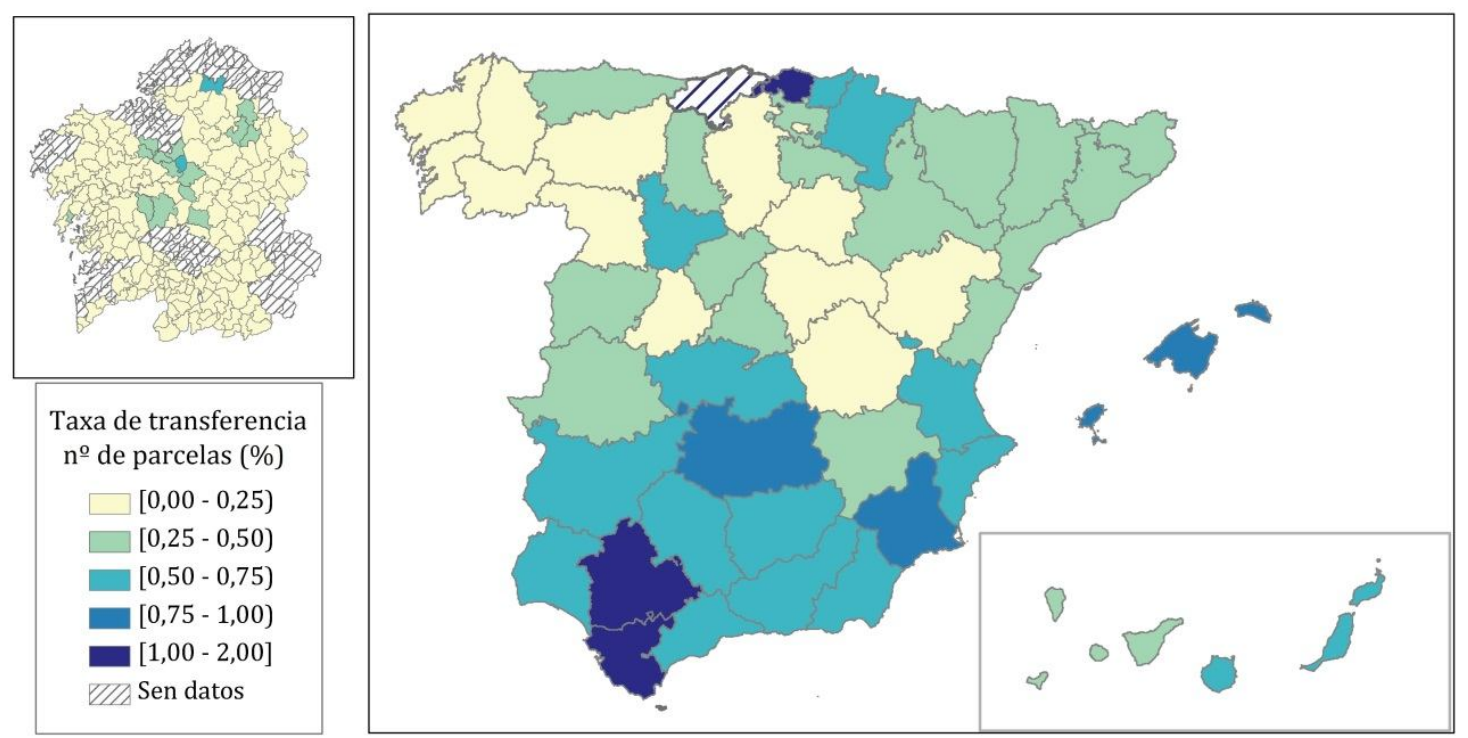

Mapa 6. Taxa de transferencia media anual do número de parcelas rústicas por concellos (esquerda) e provincias (dereita) no período 2008-2011. Elaboración propia a partir dos datos de dereito de adquisición preferente do Banco de Terras de Galicia e da Estatística de Transmisións de Dereitos de Propiedade (INE, 2015), respectivamente.

A diagnose do mercado de terras rústicas abórdase habitualmente dende a perspectiva da conservación de superficies agrarias, de aí que as taxas publicadas fagan referencia a este uso (EUROSTAT, 2015). A taxa de transferencia media anual de superficie agraria nas zonas ZEIA é do $0,16 \%$. A cifra está moi por debaixo dos valores aportados polas referencias bibliográficas, incluso considerando a diversidade de valores municipais 
(máximo de 1,18 \%): entre 3,6 e 11,8 \% en tres concellos de Valencia (Arnalte, Avellá e Roca, 1986), entre o 1 e 5 \% en dous concellos de León (Marín, 1993), 1,3 e 2\\% en dúas rexións de Valladolid e en torno ó $4 \%$ en cinco distritos de Sevilla (Sumpsi, 1986). O valor está tamén por debaixo da única taxa de transferencia referida a Galicia para nove concellos do Distrito Hipotecario de Arzúa no período 1987-1988: 0,96 \% (López, 1995). En cambio, o rango de valores da taxa de transferencia a nivel parroquial aproxímase a calquera das cifras locais aportadas por citos estudos de caso (máximo de 7,33 \%).

A cifra dista tamén das estatísticas do mercado de terras a nivel europeo: 3,1 \% nos Países Baixos, 2,7 \% en Francia, 1,4 en Italia ou 0, 62 \% en Suecia (Ciaian et al., 2012). En cambio, outras rexións de Europa Central con niveis de fragmentación da propiedade similares a Galicia presentan taxas de transferencia de superficie agraria parellas, tales como Eslovaquia cun 0,14 \%, a República Checa cun 0,21 \% ou Romanía cun 0,09 \% (Van Dijk, 2007).

Por tanto, o dinamismo do mercado de terras en Galicia non é menor que outras rexións peninsulares en canto á proporción de parcelas obxecto de compravenda (a pesar de que Galicia concentra o $20 \%$ das parcelas de rústica de España) pero si representan unha menor proporción en termos de superficie debido á característica fragmentación do parcelario galego. O mesmo acontece no contexto europeo respecto das zonas con alta fragmentación. Isto esixe comezar a puntualizar que indicadores se empregan para avaliar o dinamismo dos mercados e, sobre todo, para construír hipóteses sobre os obstáculos pois non semella que as particularidades da estrutura da propiedade freen o número de operacións pero si as expectativas de redimensionamento e reorganización por medio deste instrumento.

Por último, a taxa de transferencia de terras a mato é parella á de superficies agrarias e, ademais, a proporción de parcelas a mato obxecto de compravenda está 15 puntos porcentuais por encima da súa representación no parcelario (37 e 22 ।\%, respectivamente) (Gráfico 2). Por esta razón, detallar a análise do dinamismo segundo usos é outra variable a ter en conta á hora de aceptar preceptos sobre o dinamismo do mercado de terras en Galicia, máis tendo en conta a súa compoñente territorial e a das dinámicas de cambio de uso do solo (Corbelle e Crecente, 2014). Á vista dos resultados, a mobilidade de terras mediante compravenda implica a conservación de superficies agrarias pero tamén a valorización de superficies sen uso actual, polo menos nalgunhas rexións do territorio galego.

\subsection{Prezos}

O valor mediano é o indicador máis aconsellable para a análise dos prezos dada a distribución dos valores. Así, o prezo mediano de terras de uso agrario $\left(1,53 € / \mathrm{m}^{2}\right)$ é similar á media da enquisa de prezos de terras agrarias para Galicia no período 2008$2011,1,59 € / \mathrm{m}^{2}$ (MAGRAMA, 2013). Respecto desta fonte de información, a cifra está por encima da media para España $\left(1,00 € / \mathrm{m}^{2}\right)$; similar á de Murcia $\left(1,58 € / \mathrm{m}^{2}\right)$ ou País Vasco $\left(1,66 € / \mathrm{m}^{2}\right)$ e por debaixo de Andalucía $\left(1,93 € / \mathrm{m}^{2}\right)$, Cantabria $\left(1,99 € / \mathrm{m}^{2}\right)$, Baleares $\left(1,91 € / \mathrm{m}^{2}\right)$ ou Valencia $\left(2,30 € / \mathrm{m}^{2}\right)$. O valor tamén está por encima da media para España $\left(1,10 € / \mathrm{m}^{2}\right)$ segundo a EUROSTAT (2008-2011); próximo ó de Reino Unido (1,78 $\left.€ / \mathrm{m}^{2}\right)$ e Luxemburgo $\left(1,78 € / \mathrm{m}^{2}\right)$; moi por encima de países con taxas de transferencia semellantes como Eslovaquia $\left(0,12 € / \mathrm{m}^{2}\right)$ ou República Checa $\left(0,22 € / \mathrm{m}^{2}\right)$ pero moi inferior ó de rexións como Países Baixos $\left(4,70 € / \mathrm{m}^{2}\right)$ ou Dinamarca $\left(3,16 € / \mathrm{m}^{2}\right)$.

A relación inversa entre taxa e prezo implica que aqueles concellos, e en particular parroquias, coas maiores taxas de transferencia teñan prezos similares a países con 
mercados estables e homoxéneos como Francia $\left(0,5-0,7 € / \mathrm{m}^{2}\right)$ ou Reino Unido $(0,6-1,60$ $€ / \mathrm{m}^{2}$ ) (Ciaian et al., 2012). Deste xeito, non se pode afirmar que o prezo da terra sexa un obstáculo per se se non que vai en consonancia co funcionamento do mercado mediante compravenda como mecanismo de articulación da mobilidade de terras rústicas.

\subsection{Análise territorial}

A base de datos manexada presenta unha fonte de información excepcional para a análise sistemática da variabilidade territorial dos indicadores. López Iglesias (1995) xa sinalaba o distinto dinamismo do mercado mediante compravenda nos concellos do ámbito comarcal por el estudado. Así mesmo, as plataformas de seguimento do mercado de terras doutras rexións tamén apuntan á cada vez maior diverxencia dos valores rexionais e locais (National Statistical Institute, 2013; Savills World Research, 2014). Os resultados do traballo constatan a variabilidade de taxa dentro das zonas de especial interese agrario e tamén a importancia da análise a nivel parrroquial, especialmente no caso do bloque de concellos suroriental.

A lectura dos trazos do mapa presentado (Mapa 6) pode abordarse dende o habitual enfoque da especialización sectorial. Este enfoque emprega unha concepción do espazo na que a estrutura económica resulta o factor determinante das dinámicas territoriais, olvidando que o espazo tamén é unha instancia do natural e do social. Unha análise explicativa preliminar do dinamismo do mercado de terras mediante compravenda a partires da especialización produtiva e dimensión das explotacións agrarias non é concluínte e só apunta a unhas lóxicas tan complexas como fragmentadas (Corbelle et al., 2015).

A este respecto, introdúcense aquí dous enfoques para ampliar o marco de reflexión sobre a heteroxeneidade espacial. Por unha banda, a definición de dereitos de propiedade de Bromley (1998) transcende os mecanismos formais tradicionais de compravenda ou contratos de arrendamento e defíneos como unha construción social e institucional adaptada ó particular xeito de aproveitamento dos recursos. Con ela pon no centro da análise a relación das partes co recurso terra como factor determinante da especificidade dos mecanismos de mobilidade existentes. Por outra banda, Massey (1979) recoñece a especificidade territorial de dinámicas como o produto da particular interrelación dos grupos sociais e das formas de organización destes. Así, a compoñente territorial das dinámicas da mobilidade de terras mediante compravenda é convinte analizala en relación a outros mecanismos de mobilidade (Mapa 7) e ás distintas formas de produción e organización.

Baixo este paraugas, a diversidade territorial de dinámicas do mercado de terras rústicas mediante compravenda non só se podería explicar polo tipo de orientación produtiva (sector lácteo, vacún carne, viñedo ou horta) e dimensión das explotacións se non tamén polo modelo intensivo ou extensivo e pola condición de residencia ou absentismo dos axentes implicados na transacción (relación dos axentes coa terra segundo Bromley (1998)) ou do tipo de organización (familiar, comunitaria, cooperativa ou sociedade limitada, por exemplo, segundo Massey (1979)). A conxunción de ambos marcos introduce o interese polo perfil de vendedor (copropiedade ou absentismo) e de comprador (explotación familiar, cooperativa, sociedade...) pois estudos como os de Vranken et al. (2011) identificaron que o principal mecanismo de mobilidade de terras en réxime de copropiedade en Bulgaria era o arrendamento por parte de cooperativas agrarias. 
Grupo de concellos

Zonas non declaradas ZEIA

$\square$ Baixa mobilidade en calquera dos mecanismos

Alta mobilidade en calquera dos mecanismos

Baixa taxa de compravenda e alta presenza de réximes de tenza indirectos (arrendamento e outros)
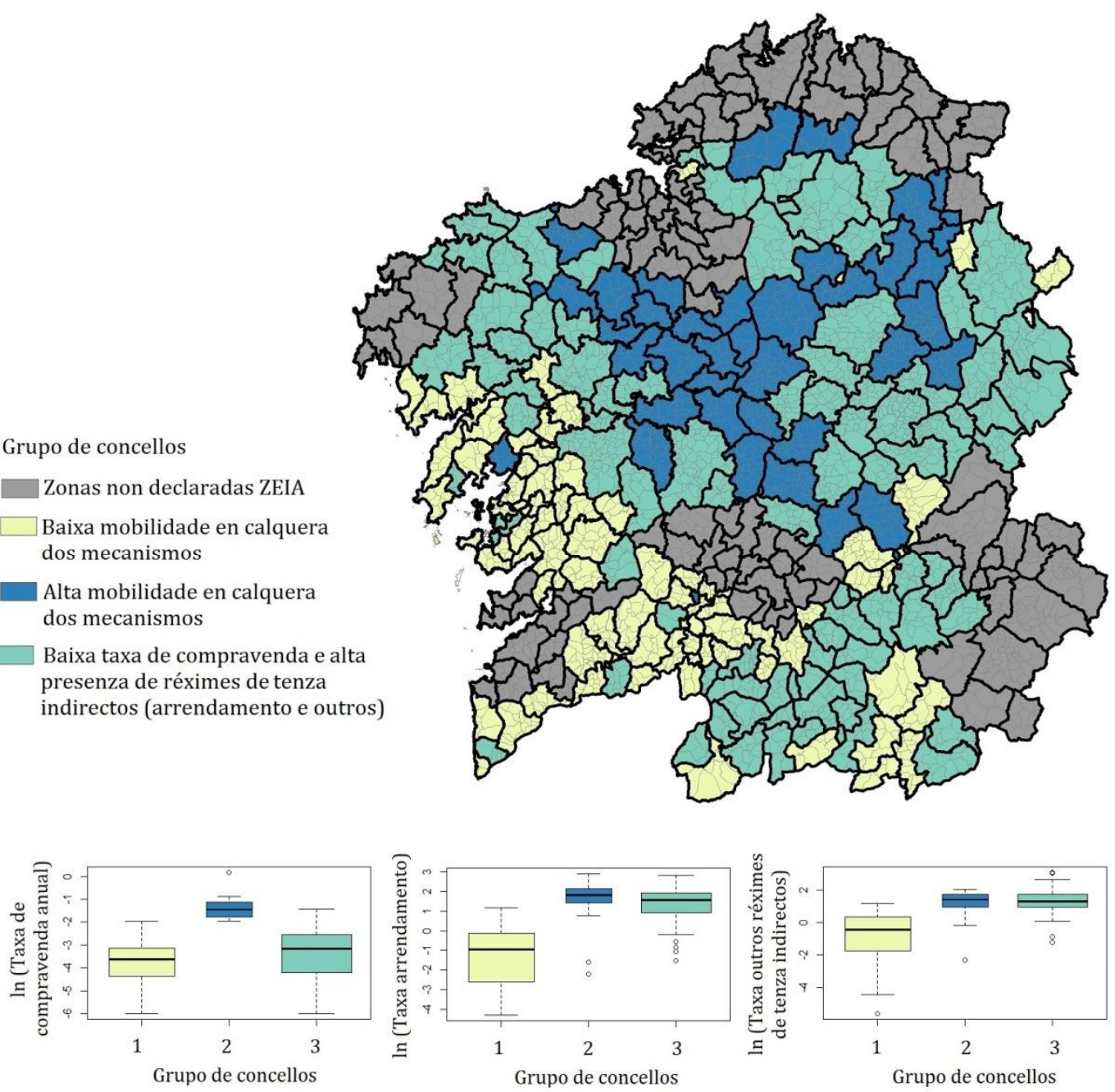

Mapa 7. Grupos de concellos resultantes da análise de conglomerados segundo a significación dos distintos mecanismos de mobilidade de terras (compravenda, arrendamento e outros réximes de tenza indirecta). A análise de conglomerados realizouse empregando a distancia euclídea entre observacións e o método de Ward coas variables estandarizadas en base á mediana e a desviación absoluta mediana. Elaboración propia a partir dos datos de adquisición preferente do Banco de Terras de Galicia no período 2008-2011, os datos do Censo Agrario (INE, 2009) e o Anuario de Estatística Agraria (Xunta de Galicia, 2009).

Deste xeito, as dinámicas do mercado de compravenda no bloque occidental poden interpretarse como unha consecuencia de que unha boa parte da superficie de rústica desta zona son Montes Veciñais en Man Común (Marey, Gómez e Díaz, 2010) e, por tanto, inalienable. As dinámicas do bloque suroriental poden lerse dende a óptica de que as formas de mobilidade informal (acordos privados non documentados, arrendamentos orais ou cesións en precario) son máis frecuentes respecto do mercado de compravenda debido a que, pola súa fisiografía e demografía, as redes de veciñanza nas aldeas son moito máis fortes (Falk e Kilpatrick, 2000; Lee et al., 2005), o modelo é máis extensivo e a taxa 
de propietarios absentistas posiblemente maior. Neste senso, Dirimanova (2008) comprobou que as redes locais xogan un papel importante nos índices de mobilidade de terras en rexións de alta fragmentación da propiedade.

A razón do exposto, resáltase que: 1) a afirmación de que a mobilidade de terras en Galicia mediante compravenda é baixa circunscríbese só a determinadas rexións da xeografía galega, 2) a significación territorial da compravenda como mecanismo de mobilidade debe ser estudada en relación a outros mecanismos e 3) a diagnose da diversidade espazo-temporal dos mecanismos de mobilidade de terras emerxe como unha ferramenta para reflexionar sobre a complexidade das distintas realidades territoriais e as súas múltiples dimensións (económica, natural, social, cultural, institucional...) sen os anteollos, preceptos, lóxicas ou expectativas dun ou outro modelo económico.

\subsection{Estrutura da propiedade e réxime de tenza}

A análise das dinámicas do mercado de terras mediante compravenda en relación ás características da estrutura da propiedade e réxime de tenza (tamaño da parcela, absentismo e copropiedade) é incompleta dada a ausencia de información sobre o parcelario global co que cotexar a súa representación.

O principal referente a este respecto é o traballo de Crecente (2010) para a comarca da Terra Chá, onde o $92 \%$ das parcelas teñen menos de 1 ha e representan o $89 \%$ da superficie; a superficie media das parcelas é de 0,40 ha; o $84 \%$ das parcelas teñen un único propietario (68 \% da superficie) e o $22 \%$ dos titulares son absentistas ( $20 \%$ da superficie).

Ó tomar esas cifras como referencia semella que o que se transfire mediante compravenda é representativo do parcelario en canto a tamaño das parcelas. A pesar de que resulte paradóxico se presupoñemos a preferencia polas parcelas de maior tamaño nun entorno de alta fragmentación, o prezo unitario da parcela diminúe conforme aumenta o tamaño. Isto tamén acontece noutras rexións como Eslovaquia (Swinnen e Vranken, 2009). Por outra banda, o precepto de que o pequeno é máis caro debe ser puntualizado polo feito de que $097 \%$ das parcelas ten menos de 1 ha e $084 \%$, menos de 0,5 ha. A pesar de que 0 prezo do segundo grupo duplique ó do primeiro, todo é pequeno (a superficie mediana é de 0,12 ha).

Os niveis de superficie en réxime de propiedade absentista que se transfire mediante compravenda duplican ós do parcelario. Pola contra, a proporción de superficie en réxime de copropiedade obxecto de compravenda é a metade da presente no parcelario. A maiores, a variabilidade espacial destas dúas variables resulta inda maior que a da taxa e 0 prezo, tal e como xa apuntaba Crecente (2010), incluso para concellos limítrofes nos que as diferentes dinámicas demográficas e réximes de herdanza non son hipóteses explicativas.

Na ausencia de información sobre o parcelario, as dúas únicas conclusión claras que se poden extraer son: 1) que no universo de parcelas de compravenda, as de propiedade absentista representan unha parte moi alta $(40 \%)$ e 2) que a compravenda non é un mecanismo que corrixa os niveis de absentismo e copropiedade do parcelario pois logo da transacción mantéñense nun 30 e $6 \%$, respectivamente.

Precisamente por esta razón, a información catastral xoga un papel relevante, non só na diagnose completa das lóxicas que rexen o mercado de terras mediante compravenda, se non tamén dos futuros retos da xestión de terras e a ordenación territorial. Por exemplo, Vranken etal. (2011) nun estudio para Bulgaria identificaron que o abandono do uso 
agrario das parcelas en réxime de copropiedade era unha pauta xeneralizada e Petrzelka, Ma e Malin (2013) nunha revisión bibliográfica sobre o absentismo en Estados Unidos apuntan á predilección deste perfil de propietarios por usos recreativos e de conservación ambiental, máis que produtivos. Os intereses de uso que rexen a transacción cobran especial interese ante as cifras de que só o $50 \%$ da superficie agraria se transmite entre residentes ou que o prezo de superficie agraria que pasa de residentes a absentistas é 1,4 veces a cando o comprador tamén é local ou ambos absentistas.

Por último, alén do enfoque cuantitativo do traballo, a execución do mesmo puxo en evidencia que a posta en marcha dunha liña de investigación en materia de administración e xestión de terras rústicas en Galicia esixe unha diagnose territorial das características do parcelario e réximes de propiedade da terra aproveitando os múltiples sistemas de información desenvoltos nos últimos anos (SIXCA, SIXPAC ou SITEGAL). Isto inclúe que a información sexa dispoñible de xeito efectivo para o propósito investigador a través das canles tamén establecidas (por exemplo, o artigo 53 do Real Decreto Lexislativo 1/2004, de 5 de marzo, polo que se aproba o texto refundido da Lei de Catastro Inmobiliario).

\section{Referencias bibliográficas}

AVELLÁ, L.; ARNALTE, E.V. (1986): "Modelos locales del mercado de la tierra en el País Valenciano", Agricultura y sociedad, 41, pp. 139-183.

BOGAERTS, T.; WILLIAMSON, I. P.; FENDEL, E. M. (2002): "The role of land administration in the accession of Central European countries to the European Union", Land Use Policy, 19 (1), pp. 29-46.

BOJNEC, Š. (2011): Land Markets in the EU Candidate Countries of Croatia, Former Yugoslav Republic of Macedonia and Turkey. (Factor Markets Working Paper, 1- September 2011). Brussels: Centre for European Policy Studies (CEPS).

BROMLEY, D. (1998): "Property regimes in economic development: lessons and policy implications", en E. Lutz [ed.]: Agriculture and the environment: perspectives on sustainable rural development, pp. 83-91. Washington, D.C.: World Bank Publications.

CALVO, S.; MÉNDEZ, G.; DÍAZ, R. (2011): “Los paisajes culturales de agras en Galicia y su dinámica evolutiva”, Ager: Revista de estudios sobre despoblación y desarrollo rural, 10 (2011), pp. 7-38.

CIAIAN, P.; KANCS, D.; SWINNEN, J.; VAN HERCK, K.; VRANKEN, L. (2012): Key Issues and Developments in Farmland Sales Markets in the EU Member States and Candidate Countries. (Factor Markets Working Paper, 12- February 2012). Brussels: Centre for European Policy Studies (CEPS).

CIAIAN, P.; KANCS, D.; SWINNEN, J. (2010): EU Land Markets and the Common Agricultural Policy. (CEPS Paperbacks, February 10). Brussels: Centre for European Policy Studies.

CIAIAN, P.; SWINNEN, J. F. (2006): “Land market imperfections and agricultural policy impacts in the new EU member states: a partial equilibrium analysis", American Journal of Agricultural Economics, 88 (4), pp. 799-815.

CORBELLE, E.; CRECENTE, R. (2014): “Urbanización, forestación e abandono. Cambios recentes na paisaxe de Galicia”, Revista Galega de Economía, 23 (1), pp. 35-51. 
CORBELLE, E; CRECENTE, R. (2014): "Evaluating IRENA indicator 'Risk of Farmland Abandonment' on a low spatial scale level: The case of Galicia (Spain)", Land Use Policy, 38 (2014), 9-15.

CORBELLE, E.; ENRÍQUEZ, M. J.; ÓNEGA, F. J.; CRECENTE, R. (2015): “El mercado de tierras rústicas en Galicia: modelos de precio y movilidad a nivel municipal". X Congreso de la Asociación de Economía Agraria. Alimentación y Territorios sostenibles desde el Sur de Europa. Córdoba: Universidad Politécnica de Valencia.

CORBELLE, E.; SANTÉ, I. (2010): “Caracterización dos cambios na superficie agrícola mediante técnicas de regresión: comarca de Terra Chá, 1956-2004", Recursos rurais: revista oficial do Instituto de Biodiversidade Agraria e Desenvolvemento Rural (IBADER), 6 (decembro 2010), pp. 23-33.

CRECENTE, R. (2010): Informe de actividades no marco do convenio 'Realización de actividades para o rural galego relativas á planificación sostible do uso do solo e da xestión de terras'. Santiago de Compostela: Axencia Galega de Desenvolvemento Rural.

CSAKI, C.; LERMAN, Z. (2000): Structural change in the farming sectors in Central and Eastern Europe. Lessons for the EU accession: second World Bank/ FAO Workshop. (World Bank Technical Paper. 495). Washington, D.C: World Bank Publications.

DALE, P.; BALDWIN, R. (2000): "Lessons Learnt from the Emerging Land Markets in Central and Eastern Europe", Qua Vadis International Conference. Prague: FIG International.

DEININGER, K. W. (2003): Land policies for growth and poverty reduction. Washington: World Bank, Oxford University Press.

DIRIMANOVA, V. (2004): "Land Market with Fragmented Landownership Rights in Bulgaria: An Institutional Approach", 94th EAAE Seminar "From households to firms with independent legal status: the spectrum of institutional units in the development of European agriculture'. Ashford (UK): European Association of Agricultural Economists.

DIRIMANOVA, V. (2008): "The importance of local networks for solving land fragmentation problems in Bulgaria", 2th Biennial Conference of the International Association for the Study of Commons. Governing shared resources: connecting local experience to global challenges. Cheltenham (England): International Association for the Study of the Commons (IASC).

ESPAÑA. DIRECCIÓN GENERAL DE CATASTRO (2015): Estadísticas catastrales. Madrid: Ministerio de Hacienda y Administraciones Públicas. < http:/ / www.catastro minhap.gob.es/ esp/ estadisticas.asp>.

ESPAÑA. INSTITUTO NACIONAL DE ESTADÍSTICA (2009): Censo Agrario 2009. Madrid: Instituto Nacional de Estadística.

ESPAÑA. INSTITUTO NACIONAL DE ESTADÍSTICA (2008-2011): Estadística de transmisiones de derechos de la propiedad. Madrid: Instituto Nacional de Estadística.

ESPAÑA. MINISTERIO DE AGRICULTURA, ALIMENTACIÓN Y MEDIO AMBIENTE (2013): Precios medios anuales de las tierras de uso agrario. Madrid: Ministerio de Agricultura, Alimentacón y Medio Ambiente. 
EUROPEAN ENVIRONMENT AGENCY (EEA) (2010): Land in Europe: prices, taxes and use patterns. Luxembourg: Office for Official Publications of the European Union.

EUROSTAT (2015): Database: Agricultural prices and price indices. Luxembourg: European Commission.

FALK, I.; KILPATRICK, S. (2000): "What is social capital? A study of interaction in a rural community", Sociologia ruralis, 40 (1), pp. 87-110.

KOPEVA, D. (2003). Land markets in Bulgaria. Journal of Land Reform, Land Settlement and Cooperatives, 2003 (3), pp. 41-58.

LEE, J.; ÁRNASON, A.; NIGHTINGALE, A.; SHUCKSMTTH, M. (2005): "Networking: social capital and identities in European rural development", Sociologia ruralis, 45 (4), pp. 269-283.

LÓPEZ IGLESIAS, E. (1995): “El mercado de tierra en Galicia: unas primeras conclusiones a partir de una investigación comarcal”, Revista Española de Economía Agraria, 1995 (174), pp. 215-253.

LÓPEZ IGLESIAS, E. (1996): Movilidad de la tierra y dinámica de las estructuras agrarias en Galicia: análisis de los obstacúlos que han frenado durante las últimas décadas las transformaciones en la estructura dimensional de las explotaciones. Madrid: Ministerio de Agricultura, Pesca y Alimentación

LORENZANA, R.; VALDÉS, B.; SINEIRO, F.; LÓPEZ, E. (2004): "La tipología de las explotaciones en función de su viabilidad económica y demográfica: aplicación a las explotaciones de bovino en Galicia”, Economía Agraria y Recursos Naturales, 2004 (8), pp. 63-85.

MAREY, M. F.; GÓMEZ, I.; DÍAZ, E. R. (2010): "Different approaches to the social vision of communal land management: the case of Galicia (Spain)", Spanish Journal of Agricultural Research, (3), pp. 848-863.

MAREY, M.; VICENTE, V.; CRECENTE, R. (2007): "Perfil del propietario forestal individual en Galicia: objetivos y prácticas de gestión en el noroeste de la comunidad", Revista Galega de Economía, 16 (1), pp. 47-70.

MARÍN RIVERO, A. (1993): El mercado de la tierra agraria: estudio de la provincia de León. León: Secretariado de Publicaciones de la Universidad de León.

MASSEY, D. (1979): “In what sense a regional problem?”, Regional Studies, 13 (2), pp. 233243.

MIRANDA, D.; CRECENTE, R.; ÁLVAREZ, M. F. (2006): “Land consolidation in inland rural Galicia, NW Spain, since 1950: An example of the formulation and use of questions, criteria and indicators for evaluation of rural development policies", Land Use Policy, 23 (4), pp. 511-520.

BULGARIA. NATIONAL STATISTICAL INSTITUTE (2013): Land market and rents in agriculture in the Republic of Bulgaria during the period 2010-2012. Sofia: National Statistical Institute.

O’FLANAGAN, P. (1996): Una Geografía Histórica de Galicia. Vigo: Xerais.

ÓNEGA, F.J.; PUPPIM DE OLIVEIRA, J.A.; CRECENTE, R. (2010). "Planning Innovations in Land Management and Governance in Fragmented Rural Areas: Two Examples from Galicia (Spain)”. European Planning Studies, 18 (5), pp. 755-773. 
PÉREZ, M. L. (1987): "Transformaciones recientes de los regímenes indirectos de tenencia de la tierra en Galicia", en G. Cano [ed.]: Estructuras y regímenes de tenencia de la tierra en España, pp. 309-322. Madrid: Secretaría General Técnica. Ministerio de Agricultura, Pesca y Alimentación.

PETRZELKA, P.; MA, Z; MALIN, S. (2013): "The elephant in the room: Absentee landowner issues in conservation and land management", Land Use Policy, 30 (1), pp. 157-166.

PLANCHUELO, E. (1971): "La propiedad rústica de los ausentes y el problema de las tierras incultas en el minifundio lucense", Revista de Estudios Agrosociales, 74 (2), pp. 77-99.

UNITED KINGDON. SAVILLS WORLD RESEARCH (2014): Market Survey. UK Agricultural Land. London: Savills Rural Research.

SINEIRO, F. (1983): "Consideracións sobre os aproveitamentos da terra en Galicia e a súa evolución no período 1930-1980, con especial referencia ao uso das terras a monte", Revista Galega de Estudios Agrarios, 9 (1983), pp. 11-34.

SUMPSI, J. M. (1986): "El mercado de la tierra y la reforma de las estructuras agrarias". Agricultura y Sociedad, (41), pp. 15-71.

SWINNEN, J;; VAN HERCK, K.; VRANKEN, L. (2012): Sales Market Regulations for Agricultural Land in EU Member States and Candidate Countries. (Factor Markets Working Paper, 12-February 2012). Brussels: Centre for European Policy Studies (CEPS).

SWINNEN, J.; VRANKEN, L. (2009): Land and EU accession: Review of the transitional restrictions by new member states on the acquisition of agricultural Real Estate. (CEPS Paperbacks - January 2009). Brussels: Centre for European Policy Studies.

TORRES LUNA, M. P.; LOIS GONZÁLEZ, R. C. (1992): “Los regímenes de tenencia en Galicia (España): el caso de las provincias interiores", Investigaciones Geográficas, 10, pp. 57-66.

VAN DIJK, T. (2007): "Complications for traditional land consolidation in Central Europe", Geoforum, 38 (3), pp. 505-511.

VAN DIJK, T.; KOPEVA, D. (2006): "Land banking and Central Europe: future relevance, current initiatives, Western European past experience", Land Use Policy, 23 (3), pp. 286-301.

VÁZQUEZ, I.; MAREY, M; SINEIRO, F.; LORENZANA, R.; GARCÍA, A.I.; PÉREZ, M. (2012): "Caracterización productiva y relaciones con el territorio de las explotaciones de bovino en Galicia". Revista Española de Estudios Agrosociales y Pesqueros, 233, pp. 69-100.

VILLARES, R. (1982): La propiedad de la tierra en Galicia: 1500-1936. 1aㅡ ed. Madrid: Siglo XXI.

VRANKEN, L.; MACOURS, K.; NOEV, N.; SWINNEN, J. (2011): "Property rights imperfections and asset allocation: co-ownership in Bulgaria", Journal of Comparative Economics 39 (2), pp. 159-175.

VRANKEN, L.; NOEV, N.; SWINNEN, J. (2004): "Fragmentation, abandonment, and coownership: transition problems of the Bulgarian land market", Quarterly Journal of International Agriculture, 43 (4), pp. 391-408. 
XUNTA DE GALICIA (2008-2011): Anuario de Estatística Agraria. Santiago de Compostela: Consellería do Medio Rural e Mar.

WALLACE, J.; WILLIAMSON, I. (2006): "Building land markets”, Land Use Policy, 23 (2), pp. 123-135.

WILLIAMSON, I. P.; ENEMARK, S.; WALLACE, J.; RAJABIFARD, A. (2010): Land administration for sustainable development. Redlands: ESRI Press.

WUNDERLICH, G. (1990): "Trends in ownership transfers of rural land", Agriculture Information Bulletin-United States Department of Agriculture, 601, pp. --.

Revista Galega de Economía: http:/ / www.usc.es/ econo/ RGE/ benvidag.htm https:// ideas.repec.org.s/ sdo/ regaec.html 